\title{
Exploring the Relationship Between Social Ties and Resilience From Evolutionary Framework
}

\author{
Sayli Agashe ${ }^{1}$, Sunil Kumar ${ }^{2}$ and Rishabh Rai $^{1 *}$ \\ ${ }^{1}$ Department of Humanities and Social Sciences, Indian Institute of Technology, Kharagpur, India, ${ }^{2}$ Department of Zoology, \\ Zakir Husain Delhi College, University of Delhi, Delhi, India
}

OPEN ACCESS

Edited by:

Tushar Singh,

Banaras Hindu University, India

Julia Gluesing,

Wayne State University, United States

Reviewed by:

Rachele Mariani,

Sapienza University of Rome, Italy

Julia Gluesing,

Wayne State University, United States

*Correspondence:

Rishabh Rai

rishabh487@gmail.com

Specialty section:

This article was submitted to

Social Networks,

a section of the journal

Frontiers in Human Dynamics

Received: 22 March 2021

Accepted: 17 May 2021

Published: 05 August 2021

Citation:

Agashe S, Kumar S and Rai R (2021)

Exploring the Relationship Between

Social Ties and Resilience From

Evolutionary Framework.

Front. Hum. Dyn 3:683755.

doi: 10.3389/fhumd.2021.683755
This conceptual paper examines the necessity and importance of social bonds and networks in building resilience to fight the COVID-19. Resilience is a quality that energizes an individual's actions and acts as a buffer to stressful events. The current article is intended to explore the evolutionary programmed behavior of the human mind to make social ties and structure. Humans have a strong need to connect and relate with other individuals by developing cooperation and perspective-taking. The ability to make social connections, group living, and sharing resources had a selective advantage in coping with physical and psychological stress. Social bonds provide resilience to people's approach while making adjustments and adapting to situations, thus presents fitness benefits at both group and individual levels. An attempt has also been made to address how social isolation as a strategy to contain the infection adversely influence body homeostasis. Finally, this article recommends health practitioners, clinicians, and researchers to encourage research on the impact of social isolation/social interaction on mental and physical health indicators.

Keywords: social connections, COVID-19, stress, resilience, evolutionary process

\section{INTRODUCTION}

The end of 2019 and the beginning of 2020 were marked by a worldwide outbreak of the COVID-19 pandemic. Coronavirus infection spread amongst the human population through droplet infections, contacting contaminated surfaces, and aerosols. The most effective strategy to contain the spread of the virus is to break the chain through social distancing, quarantine, hand hygiene, and wearing the mask (Saltzman et al., 2020). The nation-wise lockdown was imposed in various countries to contain the spread of coronavirus in March-April 2020. This global event has been tremendous in scale, with a far-reaching and profound impact on physical, psychological, social, economic, educational, and health systems across countries. The pandemic has shaken the world upside down with its nature and long-lasting effects, making us reflect on the integral and innate aspects of life. These aspects help us to survive, adjust, and function better in everyday situations. Social bonds and networks are one of those whose importance got highlighted. We acknowledge the significance of isolation during the pandemic. At the same time, there is a need to differentiate isolation without social interactions (as it happens in hospitals) and isolation at home (where an individual has interactional access with significant ones while following social distancing). In this article, we argue that isolation without social interactions may present short- and long-term undesirable effects on psychological and physical health. It is quite evident from the recommendation for home isolation given by several experts and governments (Mariani et al., 2020). In home isolation, the patient is not deprived of 
social interactions. As a result, the patient receives necessary emotional and psychological care at home. In contrast, hospitals follow stringent protocols that disallow interactions from family members and relatives. Patients are isolated in a ward wherein there is the absence of emotional and psychological support, which, in turn, may delay recovery and adversely affect mental health (Cruces et al., 2014; Cacioppo et al., 2015; Holt-Lunstad et al., 2015; Campagne, 2019).

An exciting theme which the pandemic has presented is why the absence of social interactions is pivotal for human existence. In evolution, survival and reproductive success of species depend on the balance between benefits and costs. de Waal (2008) pointed out that consequences of behavior form the basis of evolutionary analysis. Behaviors producing desirable or undesirable effects are affected by environmental and contextual factors such as the number of members in a group, predators, climate, and competition. Social isolation is one such behavioral aspect that can positively or negatively affect health, depending upon several factors. Nevertheless, the notable point is that humans have developed and relied extensively on social relationships for inclusive fitness. Whether for a short or long period, social isolation may pose adverse fitness consequences (Bailey and Moore, 2018). Against this background, the current paper argues that the evolution of enriched sociality develops resilience capability in humans during the crisis, thus producing a beneficial impact on physiological and psychological health.

\section{EVOLUTIONARY SIGNIFICANCE OF SOCIAL INTERACTIONS}

Social interactions and networks play a major role in the survival of people. Throughout the process of evolution, the essential nature of social bonds has always been emphasized (Wilson and Williams, 2013). According to the evolutionary perspective, a socially isolated and lonely individual feels unsafe and tends to be highly sensitive to danger and attacks. To feel safe and protected, our ancestors formed social connections by working in groups, sharing food, and helping each other. In stressful situations or trauma, this ability has a selective advantage of survival (Cacioppo et al., 2006a) by weakening the effects of stressful experiences through these social connections (Cohen and Wills, 1985; Wolins and Wolins, 1993). Compared to several other species, humans are not physically strong and fast. Thus, humans have an extended infancy period and development occurs within different forms of social relationships that are hierarchical with strong in-group cohesiveness (Brewer, 2004). Hence, close connections with others helped fulfill the survival and reproductive needs of humans (DeWall et al., 2011).

To achieve the goal of fitness, individuals form social groups using social strategies (Dunbar and Shultz, 2007). People in groups receive physical and mental benefits contributing to their well-being (DeWall et al., 2011). Silk (2007) also explains that fitness benefits at the group level reach the individual because of relationships. Similarly, downward causation is about the social regulation of biology in which group living influences an individual's hormonal activity. For example, women living in close proximity for a significant period have coordinated menstrual cycles. The communal group living is essential for survival because it acts as a moderator between individual and environmental requirements. Humans' capacity to adapt to diverse physical environments results from the collective knowledge and cooperative information sharing. This capacity created obligatory interdependence (Caporael and Brewer, 1995), making it a process of genetic and sociocultural coevolution, thus suggesting that the survival chances of an individual are not only dependent on his or her abilities, skills, and efforts but also on the efforts and behavior of other related individuals within a social community (Brewer, 2004).

Another aspect of the evolutionary origin of social connections is anxiety related to the individual's awareness of his mortality. For our ancestors, not having social connections was equivalent to death and social exclusion induced existential worry (Koole et al., 2006) motivated people to form long-lasting and positive relationships. The drive for social connections is considered as a desirable trait fulfilling basic survival and reproductive goals and also reducing existential anxiety associated with awareness of death (DeWall et al., 2011). Conversely, social isolation may obstruct reproductive success. Isolation refers to separating oneself from other people, thereby inhibiting social contacts and activities. Harlow and Harlow (1962) found that isolated infant monkeys showed abnormal and compulsive behavior, selfaggression, emotional pathology, deviated sexual behavior, and less attention to conspecifics. In a study conducted by Li et al. (2016), socially isolated rats displayed impairment in cognitive functioning in the form of weakened prepulse inhibition. Judge (2010) found in a study on field cricket Gryllus pennsylvanicus that socially isolated females exercised less sexual selection on males relative to females having interactional access to members of the group. Humans, like other mammals, are socially interdependent and bonded to each other (Panksepp, 2005). The evolutionary explanation of depression focuses on separation distress - one of the primary mammalian emotional systems - involved in bonding and social attachment. It gets activated by incidences of separation in infancy and early childhood and motivates reunion seeking, which supports maintaining social bonds (Watt and Panksepp, 2009).

Using Behavioral Immune System (BIS) theory, Brüne and Wilson (2020) argued that humans evolved several defense mechanisms such as avoidance of interpersonal and social interactions, neophobia, and isolating or rejecting sick individuals during the time of infection. While agreeing with the argument, it is also imperative to understand that infectious diseases in human history had not been overcome by merely following social isolation or social rejection. Instead, contagious diseases were controlled by integrating the efforts of medicine development and community participation and support. Here, as mentioned previously, we make a distinction between selfimposed isolation and social isolation. Self-imposed isolation does not preclude social interactions while simultaneously adheres to social distancing. Bailey and Moore (2018) suggested that self-imposed isolation could provide adaptive benefits to fight off pathogens. 


\section{SOCIAL INTERACTIONS, RESILIENCE, AND HEALTH}

Social connections and support are causal components of resilience. Social connections and interactions help individuals to deal with stressful situations, come out of the adverse conditions and display adaptive capacity (Marsh, 1996; FullerIglesias et al., 2008; Masten, 2014). Social connections within and between diverse groups indicate recovery from personal and community level traumas by showing the resilience quality. It can be seen in the communities with the history of volunteerism, having evolved a structure of mutual trust and self-help, thus supporting people to live through the crisis (Wilding, 2011). According to Houston and Buzzanell (2018), social connections and support promote coping behavior and psychological adaptation to emerging situations.

Post disasters, resilience can be seen as an outcome of social support (Xu and Ou, 2014; Saltzman et al., 2018). Thus, while experiencing stress and trauma, social networks become crucial to promoting resilience (Sippel et al., 2015). In resilience, an individual's traits, family, and social environment act as protective factors (Werner and Smith, 2001). Studies revealed that social support meets informational, material, and emotional needs that help building up mutual trust, interpersonal care, and shared space (Marsiglia et al., 2002; O’Donnell et al., 2002; Gralinski-Bakker et al., 2004; LaFromboise et al., 2006; Jones, 2012).

A strong association between resilience and interpersonal connections highlights the importance of social relationships for positive health outcomes. Castro and Zautra (2016) found that strong relations elicit effective short-term responses to stress and lower overall pressure exerted on the body by the process of adaptation. It suggests that social connections and relations work at the psychological, physical, and community levels in the time of stress, adversities, and traumas to help people deal with challenging and uncertain times and build resilience during this adaptation process. Also, these connections and relations let people enjoy fitness benefits at both the group and individual level (Luthar, 2006).

Deprivation of social relations causes serious physiological and psychological disturbances, making individuals weaker and incapable of facing stress and adversities effectively. Mariani et al. (2020) and Nathiya et al. (2020) found that family support enhances psychological coping strategies during the pandemic.

American Psychological Association has acknowledged the importance of social support as a response to COVID-19 (American Psychological Association, 2020). Literature has also pointed out the broader role of social support in decreasing negative symptomatology and encouraging positive adaptation post-COVID-19. Similarly, Psychological First Aid (PFA) and Skill for Psychological Recovery (SPR)-firstline disaster interventions-have also emphasized social support as a mechanism of coping (Ruzek et al., 2007; Wade et al., 2014). However, COVID-19 management demands social distancing, so it is required for people to change their ways of making connections and methods to stay connected (Saltzman et al., 2020), which would enhance a resilient response to the situation.

The lack of social interactions and unfulfilled personal and social needs cause loneliness (Cacioppo et al., 2006b; Grossman et al., 2020). Loneliness develops social pain, which is neurocognitively similar to physical pain (Eisenberger et al., 2003), thus leading to low self-esteem, declined feelings of control, and depression (Van Orden et al., 2010; Vanhalst et al., 2012; Beutel et al., 2017; Wang et al., 2018). Literature suggests that an unpredictable chronic mild stress (during the pandemic) followed by social isolation, whether objective or subjective, and inadequate social support increases morbidity, mortality, major depressive disorder, suicidal ideation, and suicide attempts (Lau et al., 2005; Cacioppo et al., 2006b; Kessler et al., 2006; Mak et al., 2009; Holt-Lunstad et al., 2015; Beller and Wagner, 2018; Wang et al., 2018; McClelland et al., 2020; Moccia et al., 2020; Sani et al., 2020).

Giallonardo et al. (2020) showed that quarantine also leads to frustration, loneliness, and worries about the future. This causes fear and errors in risk perceptions, thus leading to negative societal behavior (Shigemura et al., 2020). Particularly in COVID-19-positive patients, the experience of hospital isolation and perceived danger, uncertain physical conditions of self, and fear of dying act as risk factors and develop the symptoms of anxiety, depression, and PTSD (Bo et al., 2020; Xiang et al., 2020).

Break in social bond with the fear of losing occupation, contacting the viral infection, and restricted movements might hyperactivate the stress axes, which, in turn, adversely affect the physiological systems, including immunity (Matthews et al., 2015; Courtin and Knapp, 2017; Taylor et al., 2018; Smith and Victor, 2019), resulting in a high degree of fatality in comorbidity cases (Holt-Lunstad et al., 2015; Beller and Wagner, 2018; Boyraz et al., 2020). Conversely, interpersonal interaction and social connectedness help individuals overcome post-pandemic socioeconomic and mental health complications (Boyraz et al., 2020).

Social isolation impacts all age groups of the population. In children, lack of face-to-face interactions with peers and friends and limited outdoor activities psychologically affect them adversely. It is reflected in the form of loneliness, distress, anxiety, depression, and self-harm or suicide (Elovainio et al., 2017; Matthews et al., 2019; Galea et al., 2020; Brooks et al., 2020; Pfefferbaum and North, 2020; Wang et al., 2020). COVID19-related loneliness can have an intensified impact on adolescents and young adults (Beam and Kim, 2020). A strong association was found in older adults between social isolation and behavioral symptoms like sleep disturbance and fatigue (Cho et al., 2019).

Further, social isolation poses a detrimental effect on human physiology. Research studies have stated the significant association between social isolation and diseases such as coronary heart disease (CHD) (Orth-Gomér et al., 1993) and memory loss (Ertel et al., 2008). The loneliness that comes with social isolation shows a significant association with cardiovascular diseases, diabetes, migraine, and sleep problems (Christiansen et al., 2016). According to Seeman et al. (1987), long-standing stress and 
lower coping resources related to social isolation are responsible for immune and neuroendocrinal changes. Similarly, social isolation itself also acts as a stressor causing prolonged elevations in the hypothalamic-pituitary-adrenal (HPA) axis and sympathetic nervous system (SNS) activation (Cacioppo et al., 2015). These systems regulate the functions of various internal bodily systems for better immune functioning. The following section covers, in detail, the relationship between social isolation, stress, and physiology.

\section{PHYSIOLOGY OF STRESS AND STRESS RESPONSES}

Studies in the context of COVID-19 unanimously underline that social isolation increases the stress level in humans. An important aspect of stress resistance is the functioning of human physiology during stress. Physiological and psychological components are symbiotically related to each other. Hence, the understanding of human responses during COVID-19 requires a description of physiological responses and how it affects psychological functioning. Any environmental, physiological, and psychological stimulus that disharmonizes the homeostasis of an organism is perceived as stress (Drolet et al., 2001; Beery and Kaufer, 2015; Mumtaz et al., 2018). The stress-induced neurosensory signals are perceived and processed in the parts of the brain locus coeruleus (LC) and paraventricular nuclei (PVN) of the hypothalamus (Charmandari et al., 2005). To reestablish the homeostatic state, the body responds to these stressors via activating hypothalamic-pituitary-adrenal (HPA) and sympatho-adreno-medullary (SAM) axes (Charmandari et al., 2005). The stress stimuli elicit the release of corticotropinreleasing factor (CRF) and vasopressin (VPN) from PVN of the hypothalamus, which, in turn, stimulates the production of proopiomelanocortin-derived peptides, enkephalins, endorphins, and adrenocorticotropic hormone (ACTH) in the pituitary (Schulkin et al., 1994; Drolet et al., 2001; Goeders 2002; Dallman et al., 2003; Charmandari et al., 2005). ACTH further acts on the adrenal cortex and stimulates the production of glucocorticoids, corticosterone in rodents, and cortisol in humans. Moreover, the CRF stimulates the production of norepinephrine in the sympathetic nervous system and the peripheral tissues. The stress-response mechanism in animals has been designed to prepare the organisms to cope with the stress through "flight or fight" responses. While the stressmediated increase in plasma glucocorticoid level raises blood glucose level, an increase in norepinephrine level stimulates cardiac output, rate of respiration, heartbeat, and blood flow, and thus prepares the organism to cope with the stress through the "flight or fight" mechanism (Charmandari et al., 2005). However, prolonged stress responses, as observed in chronic stress, adversely affect various physiological functions, including immunity, and thereby make the organism vulnerable to multiple metabolic diseases and potential infections (Dallman and Bhatnagar, 2010).

Depending upon the type of stressor, different parts of the brain are activated during stress. Physical stressors like blood loss, trauma, and cold temperature activate the brainstem and hypothalamic regions (Reiche et al., 2004). On the other hand, psychological stressors like social embarrassment, examination, deadlines, and social isolation involve the activation of the amygdala, prefrontal cortex, and hippocampus for controlling emotions, learning, memory, and decisionmaking (Reiche et al., 2004). About chronic restriction movement and social isolation, stress-mediated increase in norepinephrine and serotonin level in PFC cause anxiety, learning disability, and depressive behavior (Reiche et al., 2004). It further results in suboptimal physiological functioning and impaired immune functions.

The social behavior of animals ensures better survival chances through reproductive success, protection from predators, and environmental factors (Neumann, 2009). First evolved in insects, the complex and coordinated social behavior is observed in mammals, including humans (Neumann, 2009; Blumstein et al., 2010; Ebensperger et al., 2012). The social lifestyle, in general, ensures optimal functioning of the neural, endocrine, and immune system, that, in turn, maintains a homeostatic state, reduces anxiety and depression, promotes proper cardiovascular and immune functioning and thus life expectancy (Taylor, 2006; Taylor et al., 2007; Neumann, 2009; Blumstein et al., 2010; Ebensperger et al., 2012; Beery and Kaufer, 2015). On the contrary, social isolation-induced psychological stress disturbs the coordinated functioning of neural, endocrine, and immune functions (Cruces et al., 2014). Consequently, hyper- and prolonged activation of the stress axis (HPA) causes fluctuation in the blood pressure, sleep impairment, anorexia, reduced cognitive and behavioral responses, compromised immune system (Cruces et al., 2014), and thus increased chances of comorbidity.

Chronic stress responses marked with increased production of catecholamines, opioid peptides, and glucocorticoids adversely affect the immune functions. Numerous experimental evidences support that glucocorticoids, catecholamines, and opiate peptides at elevated levels suppress both innate and adaptive immune functions (Reiche et al., 2004; Cruces et al., 2014). It has been reported that social isolation adversely affects both innate and adaptive immune systems (Cruces et al., 2014), making individuals susceptible to potential infections. Studies pertaining to address the effect of social isolation on the HPA axis and body homeostasis have been widely explored in diverse animal species, including mammals. Moreover, the responses of individuals to stress are influenced mainly by age, sex, species type, isolation regimen, and type of stressor (Hawkley et al., 2012). While chronic isolation stress increased the plasma corticosterone level in rat, mice, hamsters, pigs, and cattle (Creel and Albright, 1988; Detillion et al., 2004; Dronjak et al., 2004; Weiss et al., 2004; Hermes et al., 2006; Grippo et al., 2007a; Grippo et al., 2007b; Kanitz et al., 2009; Williams et al., 2009; Weintraub et al., 2010; Ferland and Schrader, 2011; Toth et al., 2011), in nonhuman primates such as marmosets (Cross et al., 2004; Smith et al., 2011) and rhesus monkey (Higley et al., 1992), it causes the increased production of cortisol. Though glucocorticoids support the body physiology under stress conditions, prolonged exposure to stress causes adverse effects, including compromised immune responses, and hence increased vulnerability to infections. 


\section{IMPLICATIONS AND FUTURE RECOMMENDATIONS}

The first implication is clinical intervention. In hospitals, patients can be given access to meet family members and friends by following social distancing norms. This will strengthen their mental health and enhance the coping behavior. The second implication is that systematic studies should be conducted on recovery from COVID-19 under home and hospital isolation. Although there is no data available, the encouragement given to home isolation by health experts makes it a better strategy to recuperate from the disease. Home isolation provides relational access to patients, thereby substantially limiting the deleterious effect of complete social isolation. Third, experimental studies should be conducted to test the varying levels of isolation on health. As mentioned in the article, isolation leads to psychological and physiological changes adverse to mental

\section{REFERENCES}

American Psychological Association (2020). Keeping Your Distance to Stay Safe. Retrieved from: https://www.apa.org/practice/programs/dmhi/researchinformation/social-distancing (Accessed April 15, 2021).

Bailey, N. W., and Moore, A. J. (2018). Evolutionary Consequences of Social Isolation. Trends Ecol. Evol. 33 (8), 595-607. doi:10.1016/j.tree.2018.05.008

Beam, C. R., and Kim, A. J. (2020). Psychological Sequelae of Social Isolation and Loneliness Might Be a Larger Problem in Young Adults Than Older Adults. Psychol. Trauma Theor. Res. Pract. Pol. 12 (S1), S58-S60. doi:10.1037/ tra0000774

Beery, A. K., and Kaufer, D. (2015). Stress, Social Behavior, and Resilience: Insights from Rodents. Neurobiol. Stress 1, 116-127. doi:10.1016/j.ynstr.2014.10.004

Beller, J., and Wagner, A. (2018). Disentangling Loneliness: Differential Effects of Subjective Loneliness, Network Quality, Network Size, and Living Alone on Physical, Mental, and Cognitive Health. J. Aging Health 30 (4), 521-539. doi:10.1177/0898264316685843

Beutel, M. E., Klein, E. M., Brähler, E., Reiner, I., Jünger, C., Michal, M., et al. (2017). Loneliness in the General Population: Prevalence, Determinants and Relations to Mental Health. BMC psychiatry 17 (1), 97. doi:10.1186/s12888017-1262-x

Blumstein, D. T., Ebensperger, L., Hayes, L., Vásquez, R. A., Ahern, T. H., Burger, J. R., et al. (2010). McGraw et al.Towards an integrative understanding of social behavior: new models and new opportunities. Front. Behav. Neurosci. 4, 34. doi:10.3389/fnbeh.2010.00034

Bo, H.-X., Li, W., Yang, Y., Wang, Y., Zhang, Q., Cheung, T., et al. (2020). Posttraumatic Stress Symptoms and Attitude toward Crisis Mental Health Services Among Clinically Stable Patients with COVID-19 in China. Psychol. Med. 51, 1052-1053. doi:10.1017/S0033291720000999

Boyraz, G., Legros, D. N., and Tigershtrom, A. (2020). COVID-19 and Traumatic Stress: The Role of Perceived Vulnerability, COVID-19-Related Worries, and Social Isolation. J. Anxiety Disord. 76, 102307. doi:10.1016/ j.janxdis.2020.102307

Brewer, M. B. (2004). Taking the Social Origins of Human Nature Seriously: Toward a More Imperialist Social Psychology. Pers Soc. Psychol. Rev. 8 (2), 107-113. doi:10.1207/s15327957pspr0802_3

Brooks, S. K., Webster, R. K., Smith, L. E., Woodland, L., Wessely, S., Greenberg, N., et al. (2020). The Psychological Impact of Quarantine and How to Reduce it: Rapid Review of the Evidence. The Lancet. 395(10227):912-920. doi:10.1016/ S0140-6736(20)30460-8

Brüne, M., and Wilson, D. R. (2020). Evolutionary Perspectives on Human Behavior During the Coronavirus Pandemic: Insights from Game Theory. Evol. Med. Public Health 2020 (1), 181-186. doi:10.1093/emph/eoaa034

Cacioppo, J. T., Hawkley, L. C., Ernst, J. M., Burleson, M., Berntson, G. G., Nouriani, B., et al. (2006a). Loneliness within a Nomological Net: An health, reduces immune responses, and brings disruption in neural and endocrinal activity. This can be done by creating three conditions: home isolation, hospital isolation, and hospital isolation with some interactions following social distancing. Researchers, then, can test whether there is a significant difference in the psychological and physiological parameters in these three groups.

\section{AUTHOR CONTRIBUTIONS}

SA and SK contributed to the manuscript's writing as per the design and conception of the work formulated by RR. SA has written about the psychological aspects of social isolation and social interactions. SK has written about the physiological implications of social isolation and physiological responses to stress.

Evolutionary Perspective. J. Res. Personal. 40 (6), 1054-1085. doi:10.1016/ j.jrp.2005.11.007

Cacioppo, J. T., Hughes, M. E., Waite, L. J., Hawkley, L. C., and Thisted, R. A. (2006b). Loneliness as a Specific Risk Factor for Depressive Symptoms: CrossSectional and Longitudinal Analyses. Psychol. Aging 21 (1), 140-151. doi:10.1037/0882-7974.21.1.140

Cacioppo, J. T., Cacioppo, S., Capitanio, J. P., and Cole, S. W. (2015). The Neuroendocrinology of Social Isolation. Annu. Rev. Psychol. 66, 733-767. doi:10.1146/annurev-psych-010814-015240

Campagne, D. M. (2019). Stress and Perceived Social Isolation (Loneliness). Arch. Gerontol. Geriatr. 82, 192-199. doi:10.1016/j.archger.2019.02.007

Caporael, L. R., and Brewer, M. B. (1995). Hierarchical Evolutionary Theory: There Is an Alternative, and It's Not Creationism. Psychol. Inq. 6 (1), 31-34. doi:10.1207/s15327965pli0601_2

Castro, S. A., and Zautra, A. J. (2016). Humanization of Social Relations: Nourishing Health and Resilience through Greater Humanity. J. Theor. Phil. Psychol. 36 (2), 64-80. doi:10.1037/teo0000040

Charmandari, E., Tsigos, C., and Chrousos, G. (2005). Endocrinology of the Stress Response. Annu. Rev. Physiol. 67, 259-284. doi:10.1146/ annurev.physiol.67.040403.120816

Cho, J. H.-J., Olmstead, R., Choi, H., Carrillo, C., Seeman, T. E., and Irwin, M. R. (2019). Associations of Objective versus Subjective Social Isolation with Sleep Disturbance, Depression, and Fatigue in Community-Dwelling Older Adults. Aging Ment. Health 23, 1130-1138. doi:10.1080/13607863.2018.1481928

Christiansen, J., Larsen, F. B., and Lasgaard, M. (2016). Do stress, Health Behavior, and Sleep Mediate the Association between Loneliness and Adverse Health Conditions Among Older People? Soc. Sci. Med. 152, 80-86. doi:10.1016/ j.socscimed.2016.01.020

Cohen, S., and Wills, T. A. (1985). Stress, Social Support, and the Buffering Hypothesis. Psychol. Bull. 98 (2), 310-357. doi:10.1037/0033-2909.98.2.310

Courtin, E., and Knapp, M. (2017). Social Isolation, Loneliness and Health in Old Age: a Scoping Review. Health Soc. Care Community 25 (3), 799-812. doi: $10.1111 /$ hsc. 12311

Creel, S. R., and Albright, J. L. (1988). The Effects of Neonatal Social Isolation on the Behavior and Endocrine Function of Holstein Calves. Appl. Anim. Behav. Sci. 21 (4), 293-306. doi:10.1016/0168-1591(88)90064-0

Cross, N., Pines, M. K., and Rogers, L. J. (2004). Saliva Sampling to Assess Cortisol Levels in Unrestrained Common Marmosets and the Effect of Behavioral Stress. Am. J. Primatol. 62 (2), 107-114. doi:10.1002/ajp.20005

Cruces, J., Venero, C., Pereda-Péeez, I., and Fuente, M. (2014). The Effect of Psychological Stress and Social Isolation on Neuroimmunoendocrine Communication. Cpd 20 (29), 4608-4628. doi:10.2174/ 1381612820666140130205822

Dallman, M. F., and Bhatnagar, S. (2010). Chronic Stress and Energy Balance: Role of the Hypothalamo-Pituitary-Adrenal Axis. Compr. Physiol., 179-210. doi:10.1002/cphy.cp070410 
Dallman, M. F., Pecoraro, N., Akana, S. F., La Fleur, S. E., Gomez, F., Houshyar, H., et al. (2003). Chronic Stress and Obesity: a New View of "comfort Food". Proc. Natl. Acad. Sci. 100 (20), 11696-11701. doi:10.1073/pnas.1934666100

Detillion, C. E., Craft, T. K., Glasper, E. R., Prendergast, B. J., and DeVries, A. C. (2004). Social Facilitation of Wound Healing. Psychoneuroendocrinology 29 (8), 1004-1011. doi:10.1016/j.psyneuen.2003.10.003

DeWall, C. N., Deckman, T., Pond, R. S., Jr, and Bonser, I. (2011). Belongingness as a Core Personality Trait: How Social Exclusion Influences Social Functioning and Personality Expression. J. Personal. 79 (6), 1281-1314. doi:10.1111/j.14676494.2010.00695.x

de Waal, F. B. (2008). Putting the Altruism Back into Altruism: The Evolution of Empathy. Annu. Rev. Psychol. 59, 279-300. doi:10.1146/ annurev.psych.59.103006.093625

Drolet, G., Dumont, É. C., Gosselin, I., Kinkead, R., Laforest, S., and Trottier, J. F. (2001). Role of Endogenous Opioid System in the Regulation of the Stress Response. Prog. Neuro-Psychopharmacol. Biol. Psychiatry 25 (4), 729-741. doi:10.1016/S0278-5846(01)00161-0

Dronjak, S., Gavrilović, L., Filipović, D., and Radojčić, M. B. (2004). Immobilization and Cold Stress Affect Sympatho-Adrenomedullary System and Pituitary-Adrenocortical axis of Rats Exposed to Long-Term Isolation and Crowding. Physiol. Behav. 81 (3), 409-415. doi:10.1016/j.physbeh.2004.01.011

Dunbar, R. I., and Shultz, S. (2007). Evolution in the Social Brain. science 317 (5843), 1344-1347. doi:10.1126/science.1145463

Ebensperger, L. A., Rivera, D. S., and Hayes, L. D. (2012). Direct Fitness of Group Living Mammals Varies with Breeding Strategy, Climate and Fitness Estimates. J. Anim. Ecol., 1013-1023. doi:10.1111/j.1365-2656.2012.01973.x https://www. jstor.org/stable/41682518.

Eisenberger, N. I., Lieberman, M. D., and Williams, K. D. (2003). Does Rejection Hurt? an fMRI Study of Social Exclusion. Science 302 (5643), 290-292. doi:10.1126/science.1089134

Elovainio, M., Hakulinen, C., Pulkki-Råback, L., Virtanen, M., Josefsson, K., Jokela, M., et al. (2017). Contribution of Risk Factors to Excess Mortality in Isolated and Lonely Individuals: an Analysis of Data from the UK Biobank Cohort Study. The Lancet Public Health 2 (6), e260-e266. doi:10.1016/S2468-2667(17) 30075-0

Ertel, K. A., Glymour, M. M., and Berkman, L. F. (2008). Effects of Social Integration on Preserving Memory Function in a Nationally Representative US Elderly Population. Am. J. Public Health 98 (7), 1215-1220. doi:10.2105/ AJPH.2007.113654

Ferland, C. L., and Schrader, L. A. (2011). Cage Mate Separation in Pair-Housed Male Rats Evokes an Acute Stress Corticosterone Response. Neurosci. Lett. 489 (3), 154-158. doi:10.1016/j.neulet.2010.12.006

Fuller-Iglesias, H., Sellars, B., and Antonucci, T. C. (2008). Resilience in Old Age: Social Relations as a Protective Factor. Res. Hum. Dev. 5 (3), 181-193. doi:10.1080/15427600802274043

Galea, S., Merchant, R. M., and Lurie, N. (2020). The Mental Health Consequences of COVID-19 and Physical Distancing: The Need for Prevention and Early Intervention. JAMA Intern. Med. 180 (6), 817-818. doi:10.1001/ jamainternmed.2020.1562

Giallonardo, V., Sampogna, G., Del Vecchio, V., Luciano, M., Albert, U., Carmassi, C., et al. (2020). The Impact of Quarantine and Physical Distancing Following COVID-19 on Mental Health: Study Protocol of a Multicentric Italian Population Trial. Front. Psychiatry 11. doi:10.3389/fpsyt.2020.00533

Goeders, N. E. (2002). Stress and Cocaine Addiction. J. Pharmacol. Exp. Ther. 301 (3), 785-789. doi:10.1124/jpet.301.3.785

Gralinski-Bakker, J. H., Hauser, S. T., Stott, C., Billings, R. L., and Allen, J. P. (2004). Markers of Resilience and Risk: Adult Lives in a Vulnerable Population. Res. Hum. Dev. 1 (4), 291-326. doi:10.1207/s15427617rhd0104_4

Grippo, A. J., Cushing, B. S., and Carter, C. S. (2007a). Depression-like Behavior and Stressor-Induced Neuroendocrine Activation in Female Prairie Voles Exposed to Chronic Social Isolation. Psychosomatic Med. 69 (2), 149. doi:10.1097/PSY.0b013e31802f054b

Grippo, A. J., Gerena, D., Huang, J., Kumar, N., Shah, M., Ughreja, R., et al. (2007b). Social Isolation Induces Behavioral and Neuroendocrine Disturbances Relevant to Depression in Female and Male Prairie Voles. Psychoneuroendocrinology 32 (8-10), 966-980. doi:10.1016/j.psyneuen.2007.07.004

Grossman, E. S., Hoffman, Y. S., Palgi, Y., and Shrira, A. (2020). COVID-19 Related Loneliness and Sleep Problems in Older Adults: Worries and Resilience as
Potential Moderators. Personal. individ. diff. 168, 110371. doi:10.1016/ j.paid.2020.110371

Harlow, H. F., and Harlow, M. K. (1962). Social Deprivation in Monkeys. Sci. Am. 207 (5), 130-150. doi:10.1038/scientificamerican1162-136

Hawkley, L. C., Cole, S. W., Capitanio, J. P., Norman, G. J., and Cacioppo, J. T. (2012). Effects of Social Isolation on Glucocorticoid Regulation in Social Mammals. Horm. Behav. 62 (3), 314-323. doi:10.1016/j.yhbeh.2012.05.011

Hermes, G. L., Rosenthal, L., Montag, A., and McClintock, M. K. (2006). Social Isolation and the Inflammatory Response: Sex Differences in the Enduring Effects of a Prior Stressor. Am. J. Physiol.-Regul, Integr. Comp. Physiol. 290 (2), R273-R282. doi:10.1152/ajpregu.00368.2005

Higley, J. D., Suomi, S. J., and Linnoila, M. (1992). A Longitudinal Assessment of CSF Monoamine Metabolite and Plasma Cortisol Concentrations in Young Rhesus Monkeys. Biol. Psychiatry 32 (2), 127-145. doi:10.1016/0006-3223(92) 90016-S

Holt-Lunstad, J., Smith, T. B., Baker, M., Harris, T., and Stephenson, D. (2015). Loneliness and Social Isolation as Risk Factors for Mortality: a Meta-Analytic Review. Perspect. Psychol. Sci. 10 (2), 227-237. doi:10.1177/1745691614568352

Houston, J. B., and Buzzanell, P. M. (2018). Communication and Resilience: Concluding Thoughts and Key Issues for Future Research. J. Appl. Commun. Res. 46 (1), 26-27. doi:10.1080/00909882.2018.1426691

Jones, L. (2012). Measuring Resiliency and its Predictors in Recently Discharged foster Youth. Child. Adolesc. Soc. Work J. 29 (6), 515-533. doi:10.1007/s10560012-0275-z

Judge, K. A. (2010). Female Social Experience Affects the Shape of Sexual Selection on Males. Evol. Ecol. Res. 12, 389-402.

Kanitz, E., Puppe, B., Tuchscherer, M., Heberer, M., Viergutz, T., and Tuchscherer, A. (2009). A Single Exposure to Social Isolation in Domestic Piglets Activates Behavioural Arousal, Neuroendocrine Stress Hormones, and Stress-Related Gene Expression in the Brain. Physiol. Behav. 98 (1-2), 176-185. doi:10.1016/ j.physbeh.2009.05.007

Kessler, R. C., Galea, S., Jones, R. T., and Parker, H. A. (2006). Mental Illness and Suicidality after Hurricane Katrina. Bull. World Health Organ. 84, 930-939. doi:10.2471/BLT.06.033019

Koole, S. L., Greenberg, J., and Pyszczynski, T. (2006). Introducing Science to the Psychology of the Soul: Experimental Existential Psychology. Curr. Dir. Psychol. Sci. 15 (5), 212-216. doi:10.1111/j.1467-8721.2006.00438.x

LaFromboise, T. D., Hoyt, D. R., Oliver, L., and Whitbeck, L. B. (2006). Family, Community, and School Influences on Resilience Among American Indian Adolescents in the Upper Midwest. J. Community Psychol. 34 (2), 193-209. doi:10.1002/jcop. 20090

Lau, J. T., Yang, X., Pang, E., Tsui, H. Y., Wong, E., and Wing, Y. K. (2005). SARSrelated Perceptions in Hong Kong. Emerging Infect. Dis. 11, 417-424. doi:10.3201/eid1103.040675

Li, M., Du, W., Shao, F., and Wang, W. (2016). Cognitive Dysfunction and Epigenetic Alterations of the BDNF Gene are Induced by Social Isolation During Early Adolescence. Behav. Brain Res. 313, 177-183. doi:10.1016/ j.bbr.2016.07.025

Luthar, S. S. (2006). "Resilience in Development: A Synthesis of Research across Five Decades," in Developmental Psychopathology: Risk, Disorder, and Adaptation. Editors D. Cicchetti and D. J. Cohen (New York: Wiley), 740. doi:10.1002/9780470939406.ch20

Mak, I. W. C., Chu, C. M., Pan, P. C., Yiu, M. G. C., and Chan, V. L. (2009). Longterm Psychiatric Morbidities Among SARS Survivors. Gen. Hosp. Psychiatry 31, 318-326. doi:10.1016/j.genhosppsych.2009.03.001

Mariani, R., Renzi, A., Di Trani, M., Trabucchi, G., Danskin, K., and Tambelli, R. (2020). The Impact of Coping Strategies and Perceived Family Support on Depressive and Anxious Symptomatology during the Coronavirus Pandemic (COVID-19) Lockdown. Front. Psychiatry 11, 587724. doi:10.3389/ fpsyt.2020.587724

Marsh, D. T. (1996). Families of Children and Adolescents with Serious Emotional Disturbance: Innovations in Theory, Research, and Practice. Families Ment. Health Syst. Child. adolescents: Pol. Serv. Res. 2, 75-95.

Marsiglia, F. F., Miles, B. W., Dustman, P., and Sills, S. (2002). Ties that Protect: An Ecological Perspective on Latino/a Urban Pre-adolescent Drug Use. J. Ethnic Cult. Divers. Soc. Work 11 (3-4), 191-220. doi:10.1300/J051v11n03_03

Masten, A. S. (2014). Global Perspectives on Resilience in Children and Youth. Child. Development 85 (1), 6-20. doi:10.1111/cdev.12205 
Matthews, T., Danese, A., Wertz, J., Ambler, A., Kelly, M., Diver, A., et al. (2015). Social Isolation and Mental Health at Primary and Secondary School Entry: a Longitudinal Cohort Study. J. Am. Acad. Child Adolesc. Psychiatry 54 (3), 225-232. doi:10.1016/j.jaac.2014.12.008

Matthews, T., Danese, A., Caspi, A., Fisher, H. L., Goldman-Mellor, S., Kepa, A., et al. (2019). Lonely Young Adults in Modern Britain: Findings from an Epidemiological Cohort Study. Psychol. Med. 49 (2), 268-277. doi:10.1017/ S0033291718000788

McClelland, H., Evans, J. J., Nowland, R., Ferguson, E., and O'Connor, R. C. (2020). Loneliness as a Predictor of Suicidal Ideation and Behaviour: a Systematic Review and Meta-Analysis of Prospective Studies. J. affective Disord. doi:10.1016/j.jad.2020.05.004

Moccia, L., Janiri, D., Giuseppin, G., Agrifoglio, B., Monti, L., Mazza, M., et al. (2020). Reduced Hedonic Tone and Emotion Dysregulation Predict Depressive Symptoms Severity during the COVID-19 Outbreak: An Observational Study on the Italian General Population. Int. J. Environ. Res. Public Health 18 (1), 255. doi:10.3390/ijerph18010255

Mumtaz, F., Khan, M. I., Zubair, M., and Dehpour, A. R. (2018). Neurobiology and Consequences of Social Isolation Stress in Animal Model-A Comprehensive Review. Biomed. Pharmacother. 105, 1205-1222. doi:10.1016/ j.biopha.2018.05.086

Nathiya, D., Singh, P., Suman, S., Raj, P., and Tomar, B. S. (2020). Mental Health Problems and Impact on Youth Minds during the COVID-19 Outbreak: CrossSectional (RED-COVID) Survey. Soc. Health Behav. 3 (3), 83. doi:10.4103/ SHB.SHB_32_20

Neumann, I. D. (2009). The Advantage of Social Living: Brain Neuropeptides Mediate the Beneficial Consequences of Sex and Motherhood. Front. neuroendocrinol. 30 (4), 483-496. doi:10.1016/j.yfrne.2009.04.012

O'Donnell, D. A., Schwab-Stone, M. E., and Muyeed, A. Z. (2002). Multidimensional Resilience in Urban Children Exposed to Community Violence. Child. Development 73 (4), 1265-1282. doi:10.1111/1467-8624.00471

Orth-Gomér, K., Rosengren, A., and Wilhelmsen, L. (1993). Lack of Social Support and Incidence of Coronary Heart Disease in Middle-Aged Swedish Men. Psychosomatic Med. 55 (1), 37-43. doi:10.1097/00006842199301000-00007

Panksepp, J. (2005). Affective Consciousness: Core Emotional Feelings in Animals and Humans. Conscious. Cogn. 14 (1), 30-80. doi:10.1016/j.concog.2004.10.004

Pfefferbaum, B., and North, C. S. (2020). Mental Health and the Covid-19 Pandemic. New Engl. J. Med. doi:10.1056/NEJMp2008017

Reiche, E. M. V., Nunes, S. O. V., and Morimoto, H. K. (2004). Stress, Depression, the Immune System, and Cancer. Lancet Oncol. 5 (10), 617-625. doi:10.1016/ S1470-2045(04)01597-9

Ruzek, J. I., Brymer, M. J., Jacobs, A. K., Layne, C. M., Vernberg, E. M., and Watson, P. J. (2007). Psychological First Aid. J. Ment. Health Couns. 29 (1), 17-49. doi:10.17744/mehc.29.1.5racqxjueafabgwp

Saltzman, L. Y., Pat-Horenczyk, R., Lombe, M., Weltman, A., Ziv, Y., McNamara, T., et al. (2018). Post-combat Adaptation: Improving Social Support and Reaching Constructive Growth. Anxiety, Stress, \& Coping 31 (4), 418-430. doi:10.1080/10615806.2018.1454740

Saltzman, L. Y., Hansel, T. C., and Bordnick, P. S. (2020). Loneliness, Isolation, and Social Support Factors in post-COVID-19 Mental Health. Psychol. Trauma Theor. Res. Pract. Pol. doi:10.1037/tra0000703

Sani, G., Janiri, D., Di Nicola, M., Janiri, L., Ferretti, S., and Chieffo, D. (2020). Mental Health during and after the COVID-19 Emergency in Italy. Psychiatry Clin. Neurosciences. doi:10.1111/pcn.13004

Schulkin, J., McEwen, B. S., and Gold, P. W. (1994). Allostasis, Amygdala, and Anticipatory Angst. Neurosci. Biobehavioral Rev. 18 (3), 385-396. doi:10.1016/ 0149-7634(94)90051-5

Seeman, T. E., Kaplan, G. A., Knudsen, L., Cohen, R., and Guralnik, J. (1987). Social Network Ties and Mortality Among Tile Elderly in the Alameda County Study. Am. J. Epidemiol. 126 (4), 714-723. doi:10.1093/oxfordjournals.aje.a114711

Shigemura, J., Ursano, R. J., Morganstein, J. C., Kurosawa, M., and Benedek, D. M. (2020). Public Responses to the Novel 2019 Coronavirus (2019-nCoV) in Japan: Mental Health Consequences and Target Populations. Psychiatry Clin. neurosci. 74 (4), 281. doi: $10.1111 /$ pcn. 12988

Silk, J. B. (2007). Social Components of Fitness in Primate Groups. Science 317 (5843), 1347-1351. doi:10.1126/science.1140734
Sippel, L. M., Pietrzak, R. H., Charney, D. S., Mayes, L. C., and Southwick, S. M. (2015). How Does Social Support Enhance Resilience in the Trauma Exposed Individual? Ecol. Soc. 20, 10. doi:10.5751/ES-07832-200410

Smith, K. J., and Victor, C. (2019). Typologies of Loneliness, Living Alone and Social Isolation, and Their Associations with Physical and Mental Health. Ageing Soc. 39 (8), 1709-1730. doi:10.1017/S0144686X18000132

Smith, A. S., Birnie, A. K., and French, J. A. (2011). Social Isolation Affects PartnerDirected Social Behavior and Cortisol during Pair Formation in Marmosets, Callithrix geoffroyi. Physiol. Behav. 104 (5), 955-961. doi:10.1016/ j.physbeh.2011.06.014

Taylor, S. E., Welch, W. T., Kim, H. S., and Sherman, D. K. (2007). Cultural Differences in the Impact of Social Support on Psychological and Biological Stress Responses. Psychol. Sci. 18 (9), 831-837. doi:10.1111/j.14679280.2007.01987.x

Taylor, H. O., Taylor, R. J., Nguyen, A. W., and Chatters, L. (2018). Social Isolation, Depression, and Psychological Distress Among Older Adults. J. Aging Health 30 (2), 229-246. doi:10.1177/0898264316673511

Taylor, S. E. (2006). Tend and Befriend: Biobehavioral Bases of Affiliation under Stress. Curr. Dir. Psychol. Sci. 15 (6), 273-277. doi:10.1111/j.14678721.2006.00451.x

Toth, M., Mikics, E., Tulogdi, A., Aliczki, M., and Haller, J. (2011). Post-weaning Social Isolation Induces Abnormal Forms of Aggression in Conjunction with Increased Glucocorticoid and Autonomic Stress Responses. Horm. Behav. 60 (1), 28-36. doi:10.1016/j.yhbeh.2011.02.003

Van Orden, K. A., Witte, T. K., Cukrowicz, K. C., Braithwaite, S. R., Selby, E. A., and Joiner, T. E., Jr (2010). The Interpersonal Theory of Suicide. Psychol. Rev. 117 (2), 575. doi:10.1037/a0018697

Vanhalst, J., Luyckx, K., Teppers, E., and Goossens, L. (2012). Disentangling the Longitudinal Relation between Loneliness and Depressive Symptoms: Prospective Effects and the Intervening Role of Coping. J. Soc. Clin. Psychol. 31 (8), 810-834. doi:10.1521/jscp.2012.31.8.810

Wade, D., Crompton, D., Howard, A., Stevens, N., Metcalf, O., Brymer, M., et al. (2014). Skills for Psychological Recovery: Evaluation of a post-disaster Mental Health Training Program. Disaster Health 2 (3-4), 138-145. doi:10.1080/ 21665044.2015.1085625

Wang, J., Mann, F., Lloyd-Evans, B., Ma, R., and Johnson, S. (2018). Associations between Loneliness and Perceived Social Support and Outcomes of Mental Health Problems: A Systematic Review. BMC Psychiatry 18, 156. doi:10.1186/ s12888-018-1736-5

Wang, R., Xue, D., Liu, Y., Chen, H., and Qiu, Y. (2018). The Relationship between Urbanization and Depression in China: the Mediating Role of Neighborhood Social Capital. Int. J. equity Health 17 (1), 1-10. doi:10.1186/s12939-018-0825-x

Wang, G., Zhang, Y., Zhao, J., Zhang, J., and Jiang, F. (2020). Mitigate the Effects of home Confinement on Children during the COVID-19 Outbreak. The Lancet 395 (10228), 945-947. doi:10.1016/S0140-6736(20)30547-X

Watt, D. F., and Panksepp, J. (2009). Depression: An Evolutionarily Conserved Mechanism to Terminate Separation Distress? A Review of Aminergic, Peptidergic, and Neural Network Perspectives. Neuropsychoanalysis 11 (1), 7-51. doi:10.1080/15294145.2009.10773593

Weintraub, A., Singaravelu, J., and Bhatnagar, S. (2010). Enduring and Sex-specific Effects of Adolescent Social Isolation in Rats on Adult Stress Reactivity. Brain Res. 1343, 83-92. doi:10.1016/j.brainres.2010.04.068

Weiss, I. C., Pryce, C. R., Jongen-Rêlo, A. L., Nanz-Bahr, N. I., and Feldon, J. (2004) Effect of Social Isolation on Stress-Related Behavioural and Neuroendocrine State in the Rat. Behav. Brain Res. 152 (2), 279-295. doi:10.1016/ j.bbr.2003.10.015

Werner, E. E., and Smith, R. S. (2001). Journeys from Childhood to Midlife: Risk, Resilience, and Recovery. Ithaca, NY: Cornell University Press.

Wilding, N. (2011). Exploring Community Resilience in Times of Rapid Change. Dunfermline, UK: Fiery Spirits community of Practice.

Williams, J. B., Pang, D., Delgado, B., Kocherginsky, M., Tretiakova, M., Krausz, T., et al. (2009). A Model of Gene-Environment Interaction Reveals Altered Mammary Gland Gene Expression and Increased Tumor Growth Following Social Isolation. Cancer Prev. Res. 2 (10), 850-861. doi:10.1158/19406207.CAPR-08-0238

Wilson, D., and Williams, V. (2013). Ubuntu: Development and Framework of a Specific Model of Positive Mental Health. Psychol. J. 10 (2). 
Wolin, S. J., and Wolin, S. (1993). The Resilient Self: How Survivors of Troubled. Families Rise Above Adversity. New York: Villard Books.

Xiang, Y. T., Yang, Y., Li, W., Zhang, L., Zhang, Q., Cheung, T., et al. (2020). Timely Mental Health Care for the 2019 Novel Coronavirus Outbreak Is Urgently Needed. The Lancet Psychiatry, 7(3), 228-229. doi:10.1016/S2215-0366(20)30046-8

$\mathrm{Xu}$, J., and Ou, L. (2014). Resilience and Quality of Life Among Wenchuan Earthquake Survivors: the Mediating Role of Social Support. Public health 128 (5), 430-437. doi:10.1016/j.puhe.2014.03.002

Conflict of Interest: The authors declare that the research was conducted in the absence of any commercial or financial relationships that could be construed as a potential conflict of interest.
Publisher's Note: All claims expressed in this article are solely those of the authors and do not necessarily represent those of their affiliated organizations, or those of the publisher, the editors and the reviewers. Any product that may be evaluated in this article, or claim that may be made by its manufacturer, is not guaranteed or endorsed by the publisher.

Copyright $\odot 2021$ Agashe, Kumar and Rai. This is an open-access article distributed under the terms of the Creative Commons Attribution License (CC BY). The use, distribution or reproduction in other forums is permitted, provided the original author(s) and the copyright owner(s) are credited and that the original publication in this journal is cited, in accordance with accepted academic practice. No use, distribution or reproduction is permitted which does not comply with these terms. 